\title{
Making of Free Cutting Austenitic Stainless Steels with Additions of Sulfur, Rare Earth and Bismuth
}

\author{
Wang zhiyuan ${ }^{1,}$ a , Shao zhenyao ${ }^{1, b}$, Li Zhuang ${ }^{1, \mathrm{c} *}$, Zhang Hongliang ${ }^{1, d}$, Wang \\ Jijie $^{1, e}$, Zhang Hecheng ${ }^{1, f}$, Yuan jingyun ${ }^{2, g}$ \\ ${ }^{1}$ School of Materials Science and Engineering, Shenyang Aerospace University, Shenyang \\ 110136, Liaoning, China \\ ${ }^{2}$ Shenyang heavy machinery and mine and equipment manufacturing Co., Ltd. 110015, Liaoning, \\ China \\ a1379848044@qq.com, 'bshaozhenyao1991@163.com, 'Lizhuang20047@163.com, \\ dzhanghongliang@alum.imr.ac.cn, ${ }^{\mathrm{e}}$ wangjijie@syiae.edu.cn, ${ }^{\mathrm{f}} \mathrm{C} C 690426461 @$ outlook.com, \\ ${ }^{9}$ syzjzk@163.com \\ *Lizhuang20047@163.com
}

Keywords: austenitic stainless steel; machinability; sulfur; rare earth; bismuth.

Abstract. Making of free cutting austenitic stainless steels with additions of sulfur, rare earth and bismuth were investigated through comparing to the metallurgical properties and machinabilitys. The results have shown that free-machining additives exhibit the characteristic shape of spindle shaped sulphides and rounded, globular shaped inclusions. The cutting forces of free cutting austenitic stainless steel were lower than those of an austenite stainless steel $1 \mathrm{Cr}-18 \mathrm{Ni}$-9Ti at three cutting speeds. The machinability of austenitic stainless steel was visibly improved by adding free-cutting additives, such as sulfur, rare earth and bismuth.

\section{Introduction}

In machining metals profound knowledge about the wear behaviour of the cutting tool is essential [1]. Machinability is an important criterion in materials selection and design for many applications [2]. The adhesion properties between work material and tool material in the secondary shear zone are of significant importance both regarding the energy spent in the cutting process and the performance of the cutting process itself [3].

Austenitic stainless steels are generally known to be more demanding to machine than plain carbon steels [3]. There is an important question for the machinist because of its poor machinability [4, 5]. The machinability of the steels can be improved by adding free-machining elements, such as sulfur, lead, selenium, tellurium, etc. [6]. Steelmakers have set out the reduction of environmentally harmful substances such as lead [6].

This paper reports on several aspects of the machinability by adding tulfur, RE (rare earth) and bismuth in two different austenitic stainless steels. Metallurgical properties of free cutting austenitic stainless steels were analyzed. Making of free cutting austenitic stainless steels with additions of sulfur, rare earth and bismuth were investigated through comparing to the metallurgical properties and machinabilitys.

\section{Experimental}

\section{Materials}

The ingots were prepared by using a $150 \mathrm{~kg}$ induction vacuum furnace. Specimens were $100 \mathrm{~mm}$ diameter rods which were produced by hot forging and solution treating at $1100^{\circ} \mathrm{C}$. The tool material was cemented carbide K30 tool containing WC and Co. The chemical composition of specimens for cutting test is given in Table 1 . 
Table 1 Chemical compositions (wt \%) of the experimental steels

\begin{tabular}{ccccccccccc}
\hline Steel & $\mathrm{C}$ & $\mathrm{Si}$ & $\mathrm{Mn}$ & $\mathrm{S}$ & $\mathrm{P}$ & $\mathrm{Ni}$ & $\mathrm{Cr}$ & $\mathrm{Ti}$ & $\mathrm{RE}$ & $\mathrm{Bi}$ \\
\hline $\mathrm{A}$ & 0.11 & 0.09 & 0.50 & 0.02 & 0.02 & 10.15 & 17.87 & 0.55 & - & - \\
\hline $\mathrm{B}$ & 0.09 & 0.07 & 1.470 & 0.12 & 0.01 & 9.49 & 18.34 & 0.37 & 0.04 & 0.11 \\
\hline
\end{tabular}

\section{Machinability test}

Cutting tests were performed in a CA6161A lathe under the dry cutting condition. The cutting speed was a range of $120-130 \mathrm{~m} / \mathrm{min}$. The feed rate was $0.2 \mathrm{~mm} / \mathrm{rev}$, and the depth of cut was $0.5 \mathrm{~mm}$. An optical measuring microscope and a scanning electron microscope (SEM) were used for evaluation of the morphology and quantity of the inclusions.

\section{Results}

\section{Microstructures}

The inclusions can not be found in steel A. And there are a lot of inclusions in steel B. The shape and size of the inclusions in polished specimen for steel B is shown in Fig. 1. In Fig. 1, free-machining additives exhibit the characteristic shape of punctuation and chain.



Fig.1 Optical micrographs of steel B

Fig. 2 shows a SEM micrograph of steel B. In Fig. 2, spindle shaped sulphides were observed. Sulphides appear grey. Rounded, globular shaped inclusions should be attributed to the addition of rare earth.

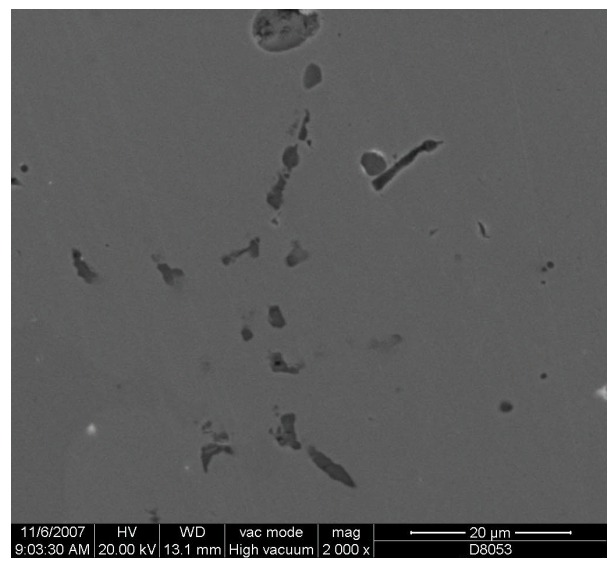

\section{Machinability}

\section{Fig. 2 SEM micrograph of steel B}

In order to measure the average abrasion depth of the flank of the tool for steel A and B, tool wear for both steels was examined using two new tools keeping the same cutting output at a cutting speed range of $120-130 \mathrm{~m} / \mathrm{min}$, feed and depth of cut of $0.2 \mathrm{~mm} / \mathrm{rev}$ and $0.5 \mathrm{~mm}$, respectively. The results of flank wear tests for both steels are presented in Fig. 3. 
In Fig. 3, the tool after turning free cutting $\mathrm{Pb}$-free austenitic stainless steel showed obviously smaller flank wear than that of after turning an austenite stainless steel $1 \mathrm{Cr}-18 \mathrm{Ni}-9 \mathrm{Ti}$ during $20 \mathrm{~min}$. That is, the progression speed of the tool wear for steel B was less than that of steel A.

Fig. 4 shows the principal force against different speed ratios for both steels. From Fig. 4, it is clear that the cutting forces generally decreased with increasing of cutting speed in the range $50-100 \mathrm{~m} / \mathrm{min}$. They were reached $349 \mathrm{~N}$ and $272 \mathrm{~N}$ at $50 \mathrm{~m} / \mathrm{min}$ cutting speed, respectively, for steel A and B. And at



Fig. 3 The flank wear curves of tools for both steels

$100 \mathrm{~m} / \mathrm{min}$ cutting speed, principal force were $343 \mathrm{~N}$ and $262 \mathrm{~N}$, respectively, for steel A and B. It was evident that the cutting forces for free cutting austenitic stainless steel were lower than those of an austenite stainless steel $1 \mathrm{Cr}-18 \mathrm{Ni}-9 \mathrm{Ti}$ at three cutting speeds.

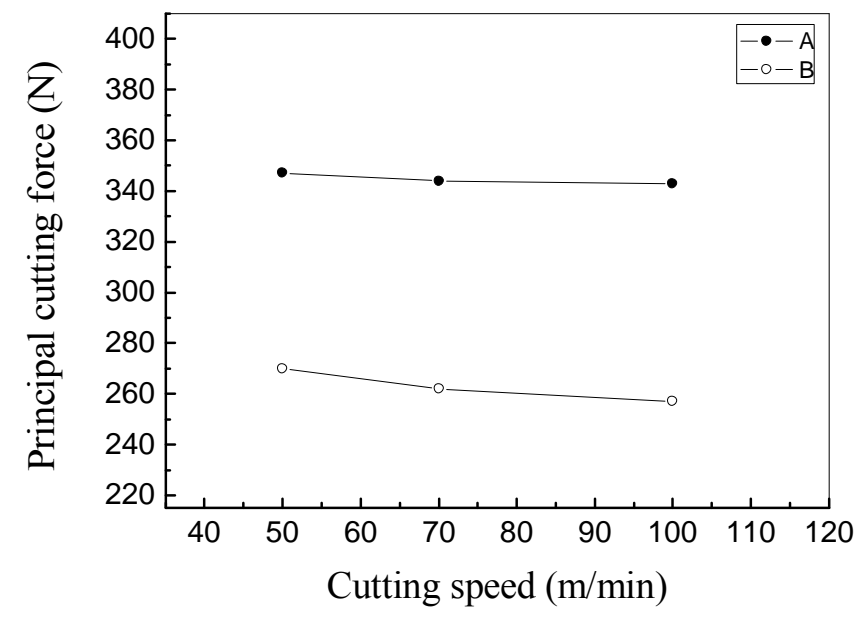

Fig. 4 Effect of cutting speed on principal force

\section{Discussion}

A significant aspect in design of cutting tools is cutting forces and should be considered in machining furthermore minimizing cutting forces affect machine component and workpiece distortion [7]. As mentioned above, the cutting forces for steel B were lower than those of steel A at three cutting speeds (Fig. 4). That is, Tool life for free cutting austenitic stainless steel was superior to that of an austenite stainless steel 1Cr-18Ni-9Ti (Fig. 3). However, Patra and his co-workers [8] found that there are only minor effects from cutting speed, square of cutting speed, square of feed and product of speed, and feed on the cutting forces. Controlled oxide inclusions contribute to the improvement of the 
machinability of austenitic stainless steels. It is expedient to add various free-machining elements, such as sulfur, rare earth and bismuth in the steel. A lot of oval inclusions were found in the surface of the specimen (Figs. 1, 2).

The inclusions are mainly composed of MnS (Figs. 1, 2). The beneficial effect of sulphur on machinability has been known now for over one hundred years. Manganese sulfide inclusion in the steel results in the formation of $\mathrm{MnS}$ films on the rake faces of the tools, and cutting force decreases because of the lubricating action of the MnS film. Sulphides are very beneficial to machining. Sulfur forms manganese sulfide, which at a certain size of the inclusions facilitates shearing and easy detachment of turnings.

RE element is also an important one because it can improve the machinability of austenitic stainless steels. Rare earth elements include 15 elements in the Periodic Table, also known as lanthanides, plus yttrium (Y) and scandium (Sc), that share chemical properties related to a similar external electronic configuration [Effect of some rare earth elements on the growth and lanthanide accumulation in different Trichoderma strains]. The S-RE-Ca system free-cutting steel exhibited the best machinability at high cutting speeds. Therefore, the S-RE system free-cutting steel had better machinability than the others in the low cutting speed range.

The addition of bismuth is a key element. It is well known that the leaded steel is currently the most common. However, lead is considered to enhance the machinability with some adverse environmental effects. Bismuth can also improve machinability of steels because it is a soft metal, like lead, with a low melting point, has a very limited solubility in solid iron, and like tellurium, is known to segregate readily to surfaces and cause embrittlement. It is considered to be distinct advantage over lead.

\section{Conclusions}

(1) A lot of inclusions in steel were observed in free cutting austenitic stainless steel. free-machining additives exhibit the characteristic shape of spindle shaped sulphides and rounded, globular shaped inclusions.

(2) The cutting forces for free cutting austenitic stainless steel were lower than those of an austenite stainless steel $1 \mathrm{Cr}-18 \mathrm{Ni}-9 \mathrm{Ti}$ at three cutting speeds. The machinability of austenitic stainless steel was visibly improved by adding free-cutting additives, such as sulfur, rare earth and bismuth.

(3) Sulphides are very beneficial to machining. The RE elements improved the machinability of austenitic stainless steel. The addition of bismuth is a key element for improving machining characteristics of austenitic stainless steels.

\section{Acknowledgement}

This work was supported by the National Natural Science Foundation of China (No.50334010), the Shenyang City Application Basic Research Project (F13-316-1-15) and Undergraduate Innovation Project of Shenyang Aerospace University (DCX140810)

\section{References}

[1] K. Johannes, B. Daniel, G. Jens, S. Johannes, G. Christian, S. Volker, W. Alexander, Study on micro texturing of uncoated cemented carbide cutting tools for wear improvement and built-up edge stabilisation, J. Mater. Process. Technol. 215 (2015) 62-70.

[2] D. Lou, K. Cui, Y. Jia. Study on the Machinability of Resulfurized Composite Free-Cutting Steels, Journal of Materials Engineering and Performance. 6 (1997) 215-218.

[3] J. Gerth, F. Gustavsson, M. Collin, G. Andersson, L.G. Nordh, J. Heinrichs, U. Wiklund, Adhesion phenomena in the secondary shear zone in turning of austenitic stainless steel and carbon steel, J. Mater. Process. Technol. 214, (2014) 1467-1481.

[4] N. Morita, M. Mori and T. Ueno, et al.: 2008 IEEE Holm Conference on Electrical Contacts, $2008,98$. 
[5] T. Akasawa, H. Sakurai and M. Nakamura: J. Mater. Process. Technol. (143-144) (2003) 66. [6] U. Leuschke, N.R. Puwada, D. Senk, Influence of micro-segregation in Pb-S-alloyed free machining steels on the surface quality of the rolled wire-rod, Metallurgia Italiana. 100 (2008) 5-11. [7] A. Davoudinejad, M.Y. Noordin, Effect of cutting edge preparation on tool performance in hard-turning of DF-3 tool steel with ceramic tools, J. Mater. Sci. Technol. 28 (2014) 4727-4736. [8] P. Karali, A.R. Shankar, S. Markus, B. Dirk, Experimental analysis of cutting forces in microdrilling of austenitic stainless steel (X5CrNi18-10), Materials and Manufacturing Processes. 30 (2015) 248-255. 